\title{
Job satisfaction evaluation based on fuzzy conjoint method with continuous fuzzy sets
}

\author{
Shahari, N., Rasmani, K. A. \\ Faculty of Computer and Mathematical Sciences, Universiti Teknologi MARA (UiTM), Malaysia
}

\begin{abstract}
Article Info
ABSTRACT

Article history:

Received Oct 9, 2019

Revised Dec 6, 2019

Accepted Dec 26, 2019

\section{Keywords:}

Continuous Fuzzy Sets

Fuzzy Conjoint Method (FCM)

Fuzzy Similarity Measure

Job Satisfaction Evaluation

Fuzzy conjoint method (FCM) is one of the available methods suggested for job satisfaction evaluation. The main feature of job satisfaction evaluation is the use of rating of agreement to indicate employee feelings and beliefs about their job. Currently the linguistic terms used for rating of agreement in FCM are represented in the form of discrete fuzzy sets. This paper investigates the potential use of continuous fuzzy sets to represent linguistic terms used in the FCM process. To investigate the consistency of the decision outcomes produced by the proposed approach, four different types of fuzzy similarity measures were used: similarity based on Matching Function, similarity based on Euclidean Distance, similarity based on Set-Theoretic and similarity based on vector. These classification outcomes are also compared with classification drawn on the basis of statistical inference. The finding of this study shows that both discrete fuzzy sets and continuous fuzzy sets produce consistent results regardless of whether the fuzzy similarity measure was used. Hence, the inclusion of other methods in FCM is particularly very useful for calculating the closeness coefficients and specifically addresses the shortcoming in FCM for job satisfaction evaluation.
\end{abstract} All rights reserved.

\section{Corresponding Author:}

Nor Azni Shahari,

Faculty of Computer and Mathematical Sciences

Universiti Teknologi MARA (UiTM), Malaysia.

Email: norazni@uitm.edu.my

\section{INTRODUCTION}

Job satisfaction is a measure that is normally used as indicator of employee satisfaction. This indicator can be used for various reasons, in particular to address employees' problems as well as dissatisfaction with the belief that they can increase their job performance and ultimately organizational performance. Hence, job satisfaction can be regarded as a very important aspect of an organization and many methods have been developed and used to measure it. One obvious feature of job satisfaction measurement is the use of rating of agreement to indicate employee feelings and beliefs about their job. The measurement process is usually carried out by providing the subject with a questionnaire containing items categorised under certain criteria related to their job such as workload, remuneration, working environment, etc. Basically, the rating of agreement is represented in the form of everyday language such as "Agree", "More or less agree", "Strongly agree" etc. These linguistic terms are considered as fuzzy terms and therefore mathematically can be defined as fuzzy sets.

A linguistic variable is a variable whose value is expressed in linguistic terms. For example, a linguistic variable "Important" can be described with linguistic terms such as "Very low", "Low", "Medium", "High", "Very high", etc. In fuzzy set theory, these terms can be represented with fuzzy membership functions. The idea of using a discrete fuzzy set in the form of fuzzy membership functions in the FCM process has been proven in various types of assessment, such as in student performance evaluation [1] and job satisfaction evaluation [2]. The scale of each fuzzy membership function is constructed on the basis of a particular situation. 
Normally, the decision maker expresses the criterion relevance linguistically. This information is transformed into a conversion scale of fuzzy membership function. Thus, some values from the interval $0-1$ with some tolerance zones are assigned to each linguistic term. Currently, in FCM, each linguistic term is expected to be represented by discrete fuzzy sets (see for examples: [3-8]). It can be observed that little effort has been made to utilise continuous fuzzy sets in the FCM process although it is expected that the use of continuous fuzzy sets may result in different decision outcomes.

The final step in the FCM process is the calculation of the degree of similarity between the fuzzy set representing all responses with a pre-defined standard fuzzy set that represents the linguistic terms. From the literature, currently only two types of similarity method have been used in FCM: either based on Euclidean Distance or based on Matching Function. Other types of similarity measure such as discussed by [9-12] are expected to be utilised. Hence, it is interesting to know the consistency of FCM in producing classification outcomes when different types of fuzzy similarity methods were employed.

The main objective of this study is to investigate how different types of fuzzy set and different types of similarity measure will affect the decision outcomes based on FCM in job satisfaction evaluation. In order to accomplish this, two performance indices - the consistency of classification outcomes based on different predefined fuzzy sets and different types of fuzzy similarity measures - are used to perform analysis of job satisfaction evaluation based on FCM.

\section{RESEARCH METHOD}

This section describes the concept of discrete fuzzy sets, continuous fuzzy sets and fuzzy similarity measures that will be used in FCM.

\subsection{The concept of discrete and continuous fuzzy sets}

Definition 1: Discrete Fuzzy Sets

Let $X$ be a non-empty set. A fuzzy set $A$ in $X$ is characterized by its membership function $\mu_{A}: x \rightarrow$ $[0,1]$ where $\mu_{A}(x)$ is interpreted as the degree of membership of element $x$ in fuzzy set $A$ for each $x \in X$, which will define the degree of belonging of $x$ in set $A$. If the value of $\mu_{A}(x)$ is nearer to 1 , then the membership degree of $x$ in $A$ will be higher. If $X=\left\{x_{1}, x_{2}, \ldots \ldots . . x_{n}\right\}$ is the finite set and $A$ is the fuzzy set in $X$, the notation used is

$A=\left\{\frac{\mu_{1}}{1}, \frac{\mu_{2}}{2}, \frac{\mu_{3}}{3}, . ., \frac{\mu_{n}}{n}\right\}$ where term $\frac{\mu_{1}}{x_{i}}, i=1,2,3 \ldots n$ signifies that $\mu_{i}$ is the grade of membership of $x_{i}$ in $A$.

Definition 2: Continuous Fuzzy Sets

Fuzzy number $A$ is a fuzzy set of a real line with a normal, fuzzy convex and continuous membership function of bounded support. Consider the triangular fuzzy number (TFN) denoted $A=(a, b, c)$ where $a, b$ and $c$ are real numbers in such a way that the membership function is defined as;

$$
\mu_{A}(x)=\left\{\begin{array}{cc}
0 & x \leq a \\
\frac{(x-a)}{b-a} & a \leq x \leq b \\
\frac{(c-x)}{c-b} & b \leq x \leq c \\
0 & x \geq c
\end{array}\right.
$$

\subsection{Fuzzy similarity measure used in FCM}

In real life we often encounter situations where we need to distinguish between similar groups. Similarity measure can be described as a function that computes the degree of similarity between two compared objects. Normally, the concept of fuzzy similarity measures is widely used in the area of decision making, artificial intelligence, and data analysis under fuzzy environment. This technique is also employed in FCM, where fuzzy similarity measure will be used to determine the final decision outcome. The larger the value of similarity measure, the greater the similarity between the two fuzzy sets.

Although various fuzzy similarity methods are currently available and potentially can be employed in FCM, it is a challenge to identify which method is more suitable for comparing fuzzy numbers. Chen et al. [13] have investigated the comparison of similarity measures of fuzzy values based on three measurements, which are: Geometric Distance model, Set-Theoretic approach, and Matching Function. Furthermore, Wang [9] proposed a new similarity method, which is known as Similarity by Elements. Beg and Ashraf [11], however, 
classified similarity measure into three categories: i) metric-based measures (Hamming Distance, Geometric Distance, and Euclidean Distance), ii) measure based on Set-Theoretic and iii) implications-based measure. Other than that, currently there are methods based on a combination of several aspects such as distance, perimeter, height and area, centre of gravity and spread (see for example [14-17]) Since the main purpose of this research is not to compare the fuzzy similarity methods, only selected similarity methods will be used. Note that other fuzzy similarity methods may be employed, depending on the suitability of the technique with regard to the application domain.

Chen et al. [13] and Hsieh and Chen [18] presented Matching Function $S$ to calculate the degree of similarity between fuzzy sets $F$ and $M$. Let $F$ and $M$ be the vector representations of fuzzy sets $F$ and $M$ respectively. Then,

$$
S^{m f}(F, M)=\frac{\bar{F} \bullet \bar{M}}{\operatorname{Max}(\bar{F} \bullet \bar{F}, \bar{M} \bullet \bar{M})},
$$

where;

$\bar{F}=$ Fuzzy set obtained from responses of respondents, and

$\bar{M}=$ Fuzzy set that is defined for $l$ linguistic term.

This similarity measure has been used in FCM by [5, 1, 19, and 20]. Fuzzy similarity based on Euclidean distance of two fuzzy sets can be defined [3] as follows:

$$
S^{e d}\left(R\left(y_{j}, A\right), F\left(x_{j}, l\right)\right)=\frac{1}{\left[1+\sqrt{\sum_{j=1}^{n}\left(\mu_{R}\left(y_{j}, A\right)-\mu_{F}\left(x_{j}, l\right)\right)^{2}}\right]},
$$

where $R\left(y_{j}, A\right)$ is the fuzzy set calculated on the basis of responses given by respondents, and $F\left(x_{j}, l\right)$ is the standard fuzzy set defined for linguistic label $l$. This similarity measure was used by [8] to evaluate job satisfaction; by [21] to evaluate software usability; by [7] to measure student expectations and by [4] to measure teacher beliefs on learning mathematics. Wang [9] introduced similarity between two fuzzy sets, $R$ and $F$, based on Set-Theoretic approach as follows:

$$
S^{s t}\left(R\left(y_{j}, A\right), F\left(x_{j}, l\right)\right)=\frac{\sum_{i=j}^{n} \frac{\operatorname{Min}\left(\mu_{R}\left(y_{j}, A\right), \mu_{F}\left(x_{j}, l\right)\right)}{\operatorname{Max}\left(\mu_{R}\left(y_{j}, A\right), \mu_{F}\left(x_{j}, l\right)\right)}}{n} .
$$

The $\operatorname{Min}(r, f)$ and $\operatorname{Max}(r, f)$ denote the minimum and maximum values of $r$ and $f$ respectively and $n$ is the number of linguistic terms used. Zhang [22] used a method based on vector to measure the similarity of two triangular fuzzy numbers to solve a multi-criteria decision-making problem. Suppose $R=\left(a_{1}, a_{2}, a_{3}\right)$ and $F=\left(b_{1}, b_{2}, b_{3}\right)$ are two triangular fuzzy numbers, the similarity was defined as follows:

$$
S^{v e}\left(R\left(y_{j}, A\right), F\left(x_{j}, l\right)\right)=\frac{2 \sum_{i=1}^{3} a_{i} b_{i}}{\sum_{i=1}^{3} a_{i} a_{i}+\sum_{i=1}^{3} b_{i} b_{i}} .
$$

\subsection{Fuzzy conjoint method for job satisfaction evaluation}

Conjoint analysis is used to determine how people value different features that make up an individual product or service. It was initially used in understanding how people make decisions. Over time, various forms of conjoint analysis have been developed, such as the Fuzzy Conjoint Method (FCM). For example, a form of preference for consumer choice in marketing using the FCM was proposed by [23 and 3]. The FCM was developed by integrating a fuzzy environment into the vector preference model. The preference model was used by [1] for student evaluation and [8] for job satisfaction evaluation.

The membership value degree for a linguistic label representing item $A$ for all respondents according to linguistic label $x_{j}=1,2,3 \ldots t$ is defined as follows; 


$$
\mu_{R}\left(y_{j}, A\right)=\sum_{i=1}^{t} W_{i} \times \mu_{B_{i}\left(x_{j}, A\right)}
$$

where, $W_{i}=\frac{w_{i}}{\sum w_{i}}$ weight that represents the level of agreement for respondent $i$ with respect to other respondents.

$\mu_{B_{i}}\left(x_{j}, A\right)=$ membership value degree for respondent $i$ for item $A$ according to linguistic label $x_{j}=1,2, . . t$

$t=$ number of linguistic labels/terms.

$A=$ an item / a question.

The following steps explain the process in FCM:

Step 1: Define the linguistic terms in terms of fuzzy set. A pre-defined fuzzy set for linguistic terms will be either in terms of a discrete fuzzy set or a triangular fuzzy number.

Step 2: Obtain the level of satisfaction from respondents using a questionnaire containing items representing criteria and sub-criteria to measure job satisfaction.

Step 3: Determine the total weight $W_{i}$ by dividing the measurement of respondent $R_{i}$ with the sum of measurement of all respondents

Step 4: Obtain the membership degree of every respondent $R_{i}$ by multiplying the weight with the fuzzy set defined in Step 1 accordingly. Then, obtain the overall membership degree value by totalling up all the membership degrees of all respondents.

Step 5: Measure the similarities of total satisfaction $R$ with all given linguistic terms in Step 1 using a selected similarity measure technique. Finally, the largest similarity value which represents a particular satisfaction level is considered to be the outcome of the FCM process.

\subsection{Illustrative example of FCM process using continuous fuzzy sets}

This section provides a numerical example of how the continuous fuzzy sets can be adopted in the current FCM process. Let the linguistic terms used to represent a linguistic variable "Satisfaction" be defined as $L_{k}=\{$ Strongly disagree, Disagree, More or less disagree, Fair, More or less agree, Agree, Strongly agree\}, where $k=1,2,3,4,5,6,7$. The linguistic value in terms of Triangular Fuzzy Number (TFN) for each linguistic term can be defined as described in Figure 1.

$\begin{array}{ll}\text { Linguistic terms } & \text { Linguistic value of TFN } \\ \text { Strongly disagree } & L_{1}=(1,1,5) \\ \text { Disagree } & L_{2}=(1,2,5) \\ \text { More or less disagree } & L_{3}=(1,3,6) \\ \text { Fair } & L_{4}=(1,4,7) \\ \text { More or less agree } & L_{5}=(2,5,7) \\ \text { Agree } & L_{6}=(3,6,7) \\ \text { Strongly agree } & L_{7}=(3,7,7)\end{array}$

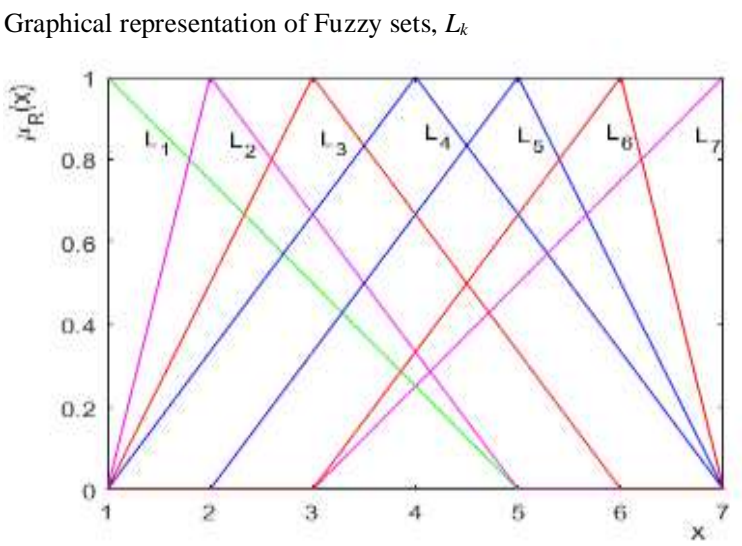

Figure 1. The proposed pre-defined continuous fuzzy numbers for linguistic variable "Satisfaction"

The next step is to obtain the membership degree for every respondent, $R_{i}$ based on the level of satisfaction given by all respondents. Let us say that there are five respondents, $M=\left\{R_{1}, R_{2}, R_{3}, R_{4}, R_{5}\right\}$ and the respondent satisfaction responses about their salary are $\{3,4,4,5,6\}$. The calculation of total weight is conducted on the basis of (5) and the result is shown in Table 1. 
Table 1. Calculation of weight based on rating agreement given by respondents

\begin{tabular}{llll}
\hline Respondent & Respondent answer & Score(w) & Weight $W_{i}$ \\
\hline 1 & More or less disagree & 3 & $3 / 22$ \\
2 & Fair & 4 & $4 / 22$ \\
3 & Fair & 4 & $4 / 22$ \\
4 & More or less agree & 5 & $5 / 22$ \\
5 & Agree & 6 & $6 / 22$ \\
& & $\sum w=22$ \\
\hline
\end{tabular}

By multiplying the total weight with the defined continuous fuzzy sets, the membership degree of every respondent $R_{i}$ is:

$R_{l}=(0.1364,0.4091,0.8182)$

$R_{2}=(0.1818,0.7273,1.2727)$

$R_{3}=(0.1818,0.7273,1.2727)$

$R_{4}=(0.4545,1.1364,1.5909)$

$R_{5}=(0.8182,1.6364,1.9091)$

This is followed by the calculation of overall membership degree:

$R=(1.7727,4.6364,6.8636)$

Finally, calculation of similarity between fuzzy sets for overall satisfaction, $R$ with fuzzy set representing each satisfaction level $L_{k}$ is conducted. In this example, similarity by vector (4) is used.

$\mathrm{S}(R$, Strongly disagree $)=0.8249$

$\mathrm{S}(R$, Disagree $)=0.8917$

$\mathrm{S}(R$, More or less disagree $)=0.9659$

$\mathrm{S}(R$, Fair $)=0.9926$

$\mathrm{S}(R$, More or less agree $)=0.9986$

$\mathrm{S}(R$, Agree $)=0.9796$

$\mathrm{S}(R$, Strongly agree $)=0.9602$

From this example, the maximum similarity value is 0.9986 , which indicates that the overall satisfaction is "More or less agree".

\section{RESULTS AND ANALYSIS}

This section provides a real-life application problem, whereby the data for job satisfaction evaluation is a collection of data obtained from 45 academic staff in a university in Malaysia. The data was collected on the basis of the 7-point Likert-scale which corresponds to 7 levels of job satisfaction. Three different experiments were conducted to achieve the objective outlined in this study. The first and the second experiments were conducted by employing the pre-defined discrete fuzzy sets used in previous research conducted by [8] and [4] respectively. The discrete fuzzy sets used to represent the satisfaction rating agreement used in Experiment 1 and Experiment 2 are shown in Table 2. For the third experiment, continuous fuzzy sets in the form of TFN are employed. The fuzzy sets are those used in the illustrative example, which was described in the previous section and depicted in Figure 1. For each experiment, four different fuzzy similarity methods, which are similarity based on Matching Function [13], similarity based on Euclidean Distance [3], similarity using Set-Theoretic approach [9] and similarity by vector [22], were used. For the purpose of validation, the classification outcomes produced by FCM were also compared with the classification derived from statistical methods obtained on the basis of the most frequent rating selected by all respondents. This method is known as the mode in statistical terminology and normally can also be represented in the form of percentage.

Table 2. Fuzzy representations of linguistic terms used in Experiment 1 and Experiment 2

\begin{tabular}{clll}
\hline Rating value & Linguistic values & Pre-defined discrete fuzzy sets $[8]$ & Pre-defined discrete fuzzy sets $[4]$ \\
\hline 1 & Strongly disagree & $\{1 / 1,0.7 / 2,0.2 / 3,0.1 / 4,0 / 5,0 / 6,0 / 7\}$ & $\{1 / 1,0.8 / 2,0.5 / 3,0.2 / 4,0 / 5,0 / 6,0 / 7\}$ \\
2 & Disagree & $\{0.6 / 1,1 / 2,0.6 / 3,0.3 / 4,0.1 / 5,0 / 6,0 / 7\}$ & $\{0.7 / 1,1 / 2,0.6 / 3,0.4 / 4,0 / 5,0 / 6,0 / 7\}$ \\
3 & More or less disagree & $\{0.2 / 1,0.7 / 2,1 / 3,0.7 / 4,0.2 / 5,0.1 / 6,0 / 7\}$ & $\{0.4 / 1,0.6 / 2,1 / 3,0.6 / 4,0.4 / 5,0 / 6,0 / 7\}$ \\
4 & Fair & $\{0 / 1,0.1 / 2,0.7 / 3,1 / 4,0.7 / 5,0.1 / 6,0 / 7\}$ & $\{0 / 1,0.3 / 2,0.7 / 3,1 / 4,0.7 / 5,0.3 / 6,0 / 7\}$ \\
5 & More or less agree & $\{0 / 1,0.1 / 2,0.2 / 3,0.7 / 4,1 / 5,0.7 / 6,0.2 / 7\}$ & $\{0 / 1,0.2 / 2,0.4 / 3,0.6 / 4,1 / 5,0.6 / 6,0.4 / 7\}$ \\
6 & Agree & $\{0 / 1,0 / 2,0.1 / 3,0.3 / 4,0.6 / 5,1 / 6,0.6 / 7\}$ & $\{0 / 1,0 / 2,0 / 3,0.4 / 4,0.6 / 5,1 / 6,0.7 / 7\}$ \\
7 & Strongly agree & $\{0 / 1,0 / 2,0 / 3,0.1 / 4,0.2 / 5,0.7 / 6,1 / 7\}$ & $\{0 / 1,0 / 2,0 / 3,0.2 / 4,0.5 / 5,0.8 / 6,1 / 7\}$ \\
\hline
\end{tabular}


The results obtained from Experiment 1 are presented in Table 3. For this experiment, the decisions tend to be consistent over all the fuzzy similarity measures except for "Interpersonal" criteria. The comparison shows that the use of different fuzzy similarity measures produces identical classification outcomes for the job satisfaction criteria "Workload", "Acknowledgement" and "Environment". For the "Interpersonal" criteria, the classification obtained by similarity methods based on Matching Function and Euclidean Distance, is 'Agree'. For the similarity measure based on Set-Theoretic approach and similarity by vector the result is "More or less agree", which is identical with the classification based on frequency. It can be observed that, although different classes were obtained for the "Interpersonal" criteria, the outcomes are about the same.

Table 4 shows the decision based on different similarity measures using the pre-defined discrete fuzzy sets used in [4] with the same linguistic terms (i.e. "Strongly disagree", "Disagree", "More or less disagree", "Fair", "More or less agree", "Agree", and "Strongly agree"). Based on the result shown in Table 4, the use of different similarity measures produces identical decision outcomes across all the job satisfaction criteria. These results are also consistent with the classification based on frequency. Further analysis of the degree of agreement on job satisfaction based on Table 3 and Table 4 show that "Workload" criteria have the highest degree of satisfaction compared to other criteria. This result is in line with findings from other research that the main factor found to contribute to the job satisfaction of academic staff is working with the students [24].

As mentioned before, for the third experiment, different pre-defined fuzzy sets for linguistic terms have been created in the form of continuous fuzzy sets (Figure 1). Quite surprisingly, the comparison of decision outcomes shows that the use of continuous fuzzy sets produces identical classification regardless of the type of fuzzy similarity measure Table 5. This result is nearly identical with the classification based on discrete fuzzy numbers obtained in Experiment 1 and Experiment 2. This implies that the triangular fuzzy number (TFN) categorised under continuous fuzzy sets (Experiment 3) used in this study produces consistent results with the classification obtained using discrete fuzzy sets (Experiment 1 and Experiment 2). The decision results demonstrate that the proposed approach of using a triangular fuzzy number (TFN) in job satisfaction evaluation using FCM is applicable and effective.

Table 3. Comparison of decision outcomes on criteria of job satisfaction using pre-defined fuzzy sets used in [8]

\begin{tabular}{|c|c|c|c|c|c|c|c|c|c|}
\hline \multirow[b]{2}{*}{ Criteria } & \multicolumn{9}{|c|}{ Satisfaction levels } \\
\hline & Similarity & $\begin{array}{l}\text { Strongly } \\
\text { disagree }\end{array}$ & Disagree & $\begin{array}{l}\text { More or } \\
\text { less } \\
\text { disagree }\end{array}$ & Fair & $\begin{array}{l}\text { More } \\
\text { or less } \\
\text { agree }\end{array}$ & Agree & $\begin{array}{l}\text { Strongl } \\
\mathrm{y} \text { agree }\end{array}$ & $\begin{array}{l}\text { Level of } \\
\text { satisfaction }\end{array}$ \\
\hline \multirow{3}{*}{ Workload } & $\mathrm{S}^{\mathrm{ed}}(\mathrm{R}, \mathrm{F})$ & 0.3772 & 0.3823 & 0.4017 & 0.4478 & 0.5919 & 0.7938 & 0.6159 & Agree \\
\hline & $S^{\text {st }}(\mathrm{R}, \mathrm{F})$ & 0.1532 & 0.1849 & 0.1817 & 0.2769 & 0.5009 & 0.5948 & 0.3062 & Agree \\
\hline & $\mathrm{S}^{\mathrm{ve}}(\mathrm{R}, \mathrm{F})$ & 0.0716 & 0.1882 & 0.3600 & 0.5523 & 0.8629 & 0.9790 & 0.8675 & Agree \\
\hline \multirow[t]{5}{*}{ Interpersonal } & $\mathrm{S}^{\mathrm{mf}}(\mathrm{R}, \mathrm{F})$ & 0.1004 & 0.2356 & 0.4022 & 0.6091 & 0.8127 & 0.8579 & 0.7244 & Agree \\
\hline & $\mathrm{S}^{\mathrm{ed}}(\mathrm{R}, \mathrm{F})$ & 0.3778 & 0.3902 & 0.4212 & 0.4946 & 0.6988 & 0.7032 & 0.5295 & Agree \\
\hline & $\mathrm{S}^{\mathrm{st}}(\mathrm{R}, \mathrm{F})$ & 0.1769 & 0.1696 & 0.2173 & 0.3804 & 0.6441 & 0.4790 & 0.2687 & More or less agree \\
\hline & $\mathrm{S}^{\mathrm{ve}}(\mathrm{R}, \mathrm{F})$ & 0.1024 & 0.2598 & 0.4690 & 0.7000 & 0.9477 & 0.9460 & 0.7387 & More or less agree \\
\hline & Percentage & 1 & 1 & 5 & 14 & 38 & 31 & 10 & More or less agree \\
\hline $\begin{array}{l}\text { Acknowledge } \\
\text { ment }\end{array}$ & $\mathrm{S}^{\mathrm{mf}}(\mathrm{R}, \mathrm{F})$ & 0.1269 & 0.2780 & 0.4515 & 0.6531 & 0.8010 & 0.8000 & 0.6498 & More or less agree \\
\hline \multirow[t]{5}{*}{ Environment } & $\mathrm{S}^{\mathrm{mf}}(\mathrm{R}, \mathrm{F})$ & 0.1208 & 0.2748 & 0.4549 & 0.6715 & 0.8353 & 0.8308 & 0.6608 & More or less agree \\
\hline & $\mathrm{S}^{\mathrm{ed}}(\mathrm{R}, \mathrm{F})$ & 0.3796 & 0.3961 & 0.4347 & 0.5251 & 0.7460 & 0.6460 & 0.4989 & More or less agree \\
\hline & $\mathrm{S}^{\mathrm{st}}(\mathrm{R}, \mathrm{F})$ & 0.1541 & 0.1729 & 0.2429 & 0.4222 & 0.6772 & 0.4247 & 0.2500 & More or less agree \\
\hline & $\mathrm{S}^{\mathrm{ve}}(\mathrm{R}, \mathrm{F})$ & 0.1223 & 0.3009 & 0.5269 & 0.7665 & 0.9676 & 0.9097 & 0.6685 & More or less agree \\
\hline & Percentage & 1 & 2 & 5 & 20 & 41 & 25 & 6 & More or less agree \\
\hline
\end{tabular}


Table 4. Comparison of decision outcomes on criteria of job satisfaction using pre-defined fuzzy sets used in [4]

\begin{tabular}{|c|c|c|c|c|c|c|c|c|c|}
\hline \multirow[b]{2}{*}{ Criteria } & \multicolumn{9}{|c|}{ Satisfaction levels } \\
\hline & Similarity & $\begin{array}{l}\text { Strongly } \\
\text { disagree }\end{array}$ & $\begin{array}{l}\text { Disagre } \\
\mathrm{e}\end{array}$ & $\begin{array}{l}\text { More or } \\
\text { less } \\
\text { disagree }\end{array}$ & Fair & $\begin{array}{l}\text { More } \\
\text { or less } \\
\text { agree }\end{array}$ & Agree & $\begin{array}{l}\text { Strongl } \\
\text { y agree }\end{array}$ & $\begin{array}{l}\text { Level of } \\
\text { satisfactiom }\end{array}$ \\
\hline Workloa & $\mathrm{S}^{\mathrm{mf}}(\mathrm{R}, \mathrm{F})$ & 0.1191 & 0.1694 & 0.3467 & 0.5716 & 0.8239 & 0.9025 & 0.8855 & Agree \\
\hline \multirow{4}{*}{$\mathrm{d}$} & $\mathrm{S}^{\mathrm{ed}}(\mathrm{R}, \mathrm{F})$ & 0.3599 & 0.3652 & 0.3964 & 0.4594 & 0.6296 & 0.7843 & 0.6880 & Agree \\
\hline & $\mathrm{S}^{\mathrm{st}}(\mathrm{R}, \mathrm{F})$ & 0.1249 & 0.1838 & 0.2317 & 0.3126 & 0.4932 & 0.5180 & 0.4150 & Agree \\
\hline & $\mathrm{S}^{\mathrm{ve}}(\mathrm{R}, \mathrm{F})$ & 0.1268 & 0.1838 & 0.3789 & 0.6408 & 0.9083 & 0.9796 & 0.9433 & Agree \\
\hline & Percentage & 0 & 2 & 3 & 10 & 22 & 38 & 25 & Agree \\
\hline \multirow{5}{*}{$\begin{array}{l}\text { Interpers } \\
\text { onal }\end{array}$} & $\mathrm{S}^{\mathrm{mf}}(\mathrm{R}, \mathrm{F})$ & 0.1807 & 0.2478 & 0.4610 & 0.6765 & 0.8719 & 0.8635 & 0.8161 & More or less agree \\
\hline & $\mathrm{S}^{\mathrm{ed}}(\mathrm{R}, \mathrm{F})$ & 0.3694 & 0.3785 & 0.4242 & 0.5104 & 0.7310 & 0.6801 & 0.5952 & More or less agree \\
\hline & $\mathrm{S}^{\mathrm{st}}(\mathrm{R}, \mathrm{F})$ & 0.1530 & 0.1927 & 0.2732 & 0.3825 & 0.6370 & 0.4383 & 0.3565 & More or less agree \\
\hline & $\mathrm{S}^{\mathrm{ve}}(\mathrm{R}, \mathrm{F})$ & 0.1930 & 0.2697 & 0.5052 & 0.7605 & 0.9640 & 0.9401 & 0.8720 & More or less agree \\
\hline & Percentage & 1 & 1 & 5 & 14 & 38 & 31 & 10 & More or less agree \\
\hline \multirow{5}{*}{$\begin{array}{l}\text { Acknowl } \\
\text { edgement }\end{array}$} & $\mathrm{S}^{\mathrm{mf}}(\mathrm{R}, \mathrm{F})$ & 0.2259 & 0.3016 & 0.5250 & 0.7174 & 0.8707 & 0.8123 & 0.7564 & More or less agree \\
\hline & $\mathrm{S}^{\mathrm{ed}}(\mathrm{R}, \mathrm{F})$ & 0.3791 & 0.3912 & 0.4477 & 0.5473 & 0.7783 & 0.6224 & 0.5568 & More or less agree \\
\hline & $\mathrm{S}^{\mathrm{st}}(\mathrm{R}, \mathrm{F})$ & 0.1780 & 0.2091 & 0.3065 & 0.4287 & 0.7326 & 0.4038 & 0.3276 & More or less agree \\
\hline & $\mathrm{S}^{\mathrm{ve}}(\mathrm{R}, \mathrm{F})$ & 0.2454 & 0.3337 & 0.5847 & 0.8192 & 0.9781 & 0.8987 & 0.8216 & More or less agree \\
\hline & Percentage & 3 & 2 & 6 & 22 & 38 & 18 & 11 & More or less agree \\
\hline \multirow{5}{*}{$\begin{array}{l}\text { Environ } \\
\text { ment }\end{array}$} & $\mathrm{S}^{\mathrm{mf}}(\mathrm{R}, \mathrm{F})$ & 0.2177 & 0.2940 & 0.5220 & 0.7259 & 0.8852 & 0.8301 & 0.7690 & More or less agree \\
\hline & $\mathrm{S}^{\mathrm{ed}}(\mathrm{R}, \mathrm{F})$ & 0.3754 & 0.3872 & 0.4424 & 0.5442 & 0.7850 & 0.6281 & 0.5555 & More or less agree \\
\hline & $\mathrm{S}^{\mathrm{st}}(\mathrm{R}, \mathrm{F})$ & 0.1721 & 0.2030 & 0.3009 & 0.4177 & 0.7243 & 0.4019 & 0.3284 & More or less agree \\
\hline & $\mathrm{S}^{\mathrm{ve}}(\mathrm{R}, \mathrm{F})$ & 0.2329 & 0.3205 & 0.5729 & 0.8172 & 0.9800 & 0.9049 & 0.8228 & More or less agree \\
\hline & Percentage & 1 & 2 & 5 & 20 & 41 & 25 & 6 & More or less agree \\
\hline
\end{tabular}

Table 5. Comparison of decision outcomes based on continuous fuzzy sets to represent the levels of satisfaction

\begin{tabular}{|c|c|c|c|c|c|c|c|c|c|}
\hline \multirow[b]{2}{*}{ Criteria } & \multicolumn{9}{|c|}{ Satisfaction levels } \\
\hline & Similirity & $\begin{array}{l}\text { Strongly } \\
\text { disagree }\end{array}$ & $\begin{array}{l}\text { Disagre } \\
\mathrm{e}\end{array}$ & $\begin{array}{l}\text { More or } \\
\text { less } \\
\text { disagree }\end{array}$ & Fair & $\begin{array}{l}\text { More } \\
\text { or less } \\
\text { agree }\end{array}$ & Agree & $\begin{array}{l}\text { Strongl } \\
\text { y agree }\end{array}$ & $\begin{array}{l}\text { Level of } \\
\text { satisfaction }\end{array}$ \\
\hline \multirow{3}{*}{ Workload } & $\mathrm{S}^{\mathrm{ed}}(\mathrm{R}, \mathrm{F})$ & 0.1532 & 0.1766 & 0.2240 & 0.2857 & 0.4769 & 0.7180 & 0.4629 & Agree \\
\hline & $\mathrm{S}^{\mathrm{st}}(\mathrm{R}, \mathrm{F})$ & 0.4228 & 0.4793 & 0.5835 & 0.6849 & 0.8686 & 0.9510 & 0.9042 & Agree \\
\hline & $\mathrm{S}^{\mathrm{ve}}(\mathrm{R}, \mathrm{F})$ & 0.7395 & 0.8192 & 0.9120 & 0.9600 & 0.9929 & 0.9992 & 0.9932 & Agree \\
\hline \multirow{4}{*}{ Interpersonal } & $\mathrm{S}^{\mathrm{ed}}(\mathrm{R}, \mathrm{F})$ & 0.1656 & 0.1929 & 0.2531 & 0.3360 & 0.6388 & 0.5384 & 0.3720 & More or less agree \\
\hline & $\mathrm{S}^{\mathrm{st}}(\mathrm{R}, \mathrm{F})$ & 0.4426 & 0.5038 & 0.6130 & 0.7182 & 0.9213 & 0.8949 & 0.8517 & More or less agree \\
\hline & $\mathrm{S}^{\mathrm{ve}}(\mathrm{R}, \mathrm{F})$ & 0.7703 & 0.8458 & 0.9328 & 0.9739 & 0.9980 & 0.9959 & 0.9850 & More or less agree \\
\hline & Percentage & 1 & 1 & 5 & 14 & 38 & 31 & 10 & More or less agree \\
\hline $\begin{array}{l}\text { Acknowledge } \\
\text { ment }\end{array}$ & $\mathrm{S}^{\mathrm{mf}}(\mathrm{R}, \mathrm{F})$ & 0.5251 & 0.5904 & 0.7424 & 0.8943 & 0.9865 & 0.9190 & 0.8563 & More or less agree \\
\hline \multirow[t]{5}{*}{ Environment } & $\mathrm{S}^{\mathrm{mf}}(\mathrm{R}, \mathrm{F})$ & 0.5255 & 0.5905 & 0.7421 & 0.8937 & 0.9859 & 0.9196 & 0.8565 & More or less agree \\
\hline & $\mathrm{S}^{\mathrm{ed}}(\mathrm{R}, \mathrm{F})$ & 0.1728 & 0.2026 & 0.2718 & 0.3713 & 0.7791 & 0.4678 & 0.3369 & More or less agree \\
\hline & $\mathrm{S}^{\mathrm{st}}(\mathrm{R}, \mathrm{F})$ & 0.4566 & 0.5206 & 0.6326 & 0.7394 & 0.9562 & 0.8628 & 0.8214 & More or less agree \\
\hline & $\mathrm{S}^{\mathrm{ve}}(\mathrm{R}, \mathrm{F})$ & 0.7862 & 0.8593 & 0.9431 & 0.9804 & 0.9995 & 0.9926 & 0.9793 & More or less agree \\
\hline & Percentage & 1 & 2 & 5 & 20 & 41 & 25 & 6 & More or less agree \\
\hline
\end{tabular}

\section{CONCLUSION}

This paper has presented a study of the potential of using continuous fuzzy sets in the analysis of job satisfaction using FCM. Two different pre-defined discrete fuzzy sets representing the level of satisfaction are compared with pre-defined continuous fuzzy sets using four different fuzzy similarity measures to predict the satisfaction level of four job satisfaction criteria. The finding of this study shows that both the discrete and continuous fuzzy sets produced consistent classification outcomes. These results were obtained regardless of the fuzzy similarity measure employed in FCM. This implies that fuzzy similarity measure has little impact on the consistency of job satisfaction evaluation using FCM. This result also indicates that it is reasonable to use the continuous fuzzy sets to express users' evaluation of job satisfaction based on FCM. Moreover, the outcome of this study also strengthens previous research findings, which suggest the suitability of FCM for the analysis of job satisfaction. 


\section{ACKNOWLEDGEMENTS}

This work was supported by Universiti Teknologi MARA, Malaysia under grant number 600IRMI/PTB 5/3 (061/2018).

\section{REFERENCES}

[1] R. Biswas, "An Application of Fuzzy Sets in Students' Evaluation," Fuzzy Sets and Systems, vol. 74, no. 2, pp. 187194, September 1995.

[2] R. H. Abiyev, et al., "Measurement of Job Satisfaction Using Fuzzy Sets," Procedia Computer Science, vol. 102, pp. 294-301, 2016.

[3] I. B. Turksen and I. A. Willson, "A fuzzy set preference model for consumer choice," Fuzzy Sets and Systems, vol. 68, no. 3, pp. 253-266, December 1994.

[4] M. A. Lazim and M. T. Abu Osman, " Measuring Teachers' Beliefs about Mathematics: A Fuzzy Set Approach," International Journal of Social Sciences, vol. 4, no. 9, pp. 1816-1820, 2009.

[5] E. Baheri, et al., "A fuzzy conjoint analysis approach for evaluating credit card services: A case study of Iranian bank," African Journal of Business Management, vol. 5, no. 7, pp. 2753-2765, April 2011.

[6] M. A. Lazim, et al., "Fuzzy Set Conjoint Model in Describing Students' Perceptions on Computer Algebra System Learning Environment," International Journal of Computer Science Issues (IJCSI), vol. 8, no. 2, pp. 92-97, March 2011.

[7] N. Sarala and R. Kavitha, "Fuzzy conjoint model in measuring students' expectation and teachers' beliefs on learning mathematics," International Journal of Advanced Trends in Engineering, Science and Technology (IJATEST), vol. 2, no. 2, pp. 6-10, March 2017.

[8] K. A. Rasmani and N. A. Shahari, "Job Satisfaction Evaluation Using Fuzzy Approach," Third International Conference on Natural Computation (ICNC 2007), Haikou, pp. 544-548, 2007.

[9] W.-J. Wang, "New similarity measures on fuzzy sets and on elements," Fuzzy Sets and Systems, vol. 85, no. 3, pp. 305-309, February 1997.

[10] Z. C. Johanyák and S. Kovács "Distance based similarity measures of fuzzy sets," in 3rd Slovakian-Hungarian Joint Symposium on Applied Machine Intelligence, Herl'any, Slovakia, pp. 265-276, January 21-22 2005.

[11] I. Beg and S. Ashraf, "Similarity Measures for Fuzzy Sets," Applied and Computational Mathematics, vol. 8, no. 2, pp. 192-202, March 2009.

[12] R. Chutia and M. K. Gogoi, "Fuzzy risk analysis in poultry farming using a new similarity measure on generalized fuzzy numbers," Computers \& Industrial Engineering, vol. 115, pp. 543-558, January 2018.

[13] S. M. Chen, et al., "A comparison of similarity measures of fuzzy values," Fuzzy sets and systems, vol. 72, no.1, pp. 79-89, May 1995.

[14] K. Patra and S. K. Mondal, "Fuzzy risk analysis using area and height based similarity measure on generalized trapezoidal fuzzy numbers and its application," Applied Soft Computing, vol. 28, pp. 276-284, March 2015.

[15] H. A. Khorshidi and S. Nikfalazar, "An improved similarity measure for generalized fuzzy numbers and its application to fuzzy risk analysis," Applied Soft Computing, vol. 52, pp. 478-486, March 2017.

[16] N. A. M. Saffie, et al., "Similarity Measure for Fuzzy Number Based on Distances and Geometric Shape Characteristics," in Proceedings of the Third International Conference on Computing, Mathematics and Statistics (iCMS2017), Langkawi, Malaysia., pp. 159-166, March 2019.

[17] N. Ramli, et al., "Fuzzy time series forecasting model with natural partitioning length approach for predicting the unemployment rate under different degree of confidence," AIP Conference Proceedings, vol. 1870, no. 1, 2017.

[18] C.-H. Hsieh and S.-H. Chen, "A model and algorithm of fuzzy product positioning," Information Sciences, vol. 121, no. 1-2, pp. 61-82, December 1999.

[19] Y. M. Yusoff, et al., "Evaluation of Graduates' Performance Using Fuzzy Approach," Procedia - Social and Behavioral Sciences, vol. 102, pp. 64-73, November 2013.

[20] N. M. I. T. Yaakub, et al., "Fuzzy Conjoint Modelling in Studying User Willingness to Switch to Bicycle as Transportation in Ipoh City," Journal of Physics: Conference Series, vol. 1049, no. 1, p. 012045, July 2018.

[21] Y. H. Yahaya and N. Mohamad, "Designing Software Usability Measurement Using Fuzzy Set Conjoint Model," in 2011 International Conference on Computer Communication and Management, vol. 5, pp. 582-576, 2011.

[22] L. Zhang, et al., "Some Similarity Measures for Triangular Fuzzy Number and Their Applications in Multiple Criteria Group Decision-Making," Journal of Applied Mathematics, vol. 2013, p. 7, March 2013.

[23] I. B. Turksen, "Fuzzy expert systems for IE/OR/MS," Fuzzy Sets and Systems, vol. 51, no. 1, pp. 1-27, October 1992.

[24] I. H. Amazt and A. R. Idris, "Lecturers' Satisfaction towards University Management \& Decision-making Styles in some Malaysian Public Universities," Procedia Social and Behavioral Sciences, vol. 15, pp. 3957-3970, 2011. 